\title{
4
}

\section{Social Networking and Science Research: The MIT-UPV and Metal 2.0 Cases}

\author{
Gil Pechuán Ignacio, Conesa Garcia M. Pilar and Peris Ortiz Marta \\ Business Management Department, \\ Technical University of Valencia, Valencia, \\ Spain
}

"Social connections are one of our hallmarks. It has often been considered that these connections are what distinguish us from animals or the lack of civilization." N.A.

Christakis, J. H. Fowler

\section{Introduction}

The value of social networking for business isn't so clear but in other areas it has been very advanced, as in the world of collaborative research and business at the international level, can affect joint enterprise (enterprise-level) is displayed as shown in the results of the collaboration project Networking between MIT and the UPV (http://mitupv.mit.edu) and UPV and AIMME1 (http://www.metal20.org/).

Most of the measurable benefits such as improved collaboration and multimedia documentation are already in place. In terms of all the components of social networking, being on a single platform, we already have that, too, in the form of unified communications (UC).

\section{2. "MIT-UPV exchange"}

This experience is a Web-based co-operative learning project between the Massachusetts Institute of Technology (MIT) in the USA and the Universidad Politécnica de Valencia (UPV) in Spain which has been underway since 2000. Its aim is to put in contact technological students in Valencia (Spain) and technological students in Boston (USA) by means of a jointly developed interactive website. This website is an open platform that allows the registered students to interact with each other; building a technological social networking not only by using text-based messages (including a built-in chat facility), but also by uploading and downloading multimedia files, i.e. videos and graphics created by the students themselves. The contents of the website are updated in real time and are fully developed and controlled by the participating students themselves, so as to reflect their interests, views and other cultural and social components.

${ }^{1}$ Metallurgical technology institute http://www.aimme.es 


\subsection{Project's rationale}

The Internet, in general, and the World Wide Web, in particular, represent an emerging medium for teaching, and their significant potential for the teaching/learning in a collaborative format. In order to put the impact of Web 2.0 in general and particularly the social networking into perspective from a future societal standpoint (for the students), it must first be seen from the context of how the next generation of services that are available online, specifically designed for ensuring a high degree of collaboration, information sharing, and support for knowledge-based.

Such projects are aligned with the demands of what Manuel Castells called network society.

The living environment that we have outside the classroom, in a visual world that is increasingly more technologized, makes the number of inputs of information and knowledge received outside the classroom far exceeds the amount received in them. Such a large amount of knowledge and information our students do not receive in an organized manner, in contrast to received wisdom within their educational time sequences where the transmission of knowledge is much more organized and regulated. Nowadays, it is a reality that media communication and human relations at a distance and through the network are a universal phenomenon in almost all over the world to a greater or lesser extent. This fact and the circumstances have to be assumed by the educational process and its human componentsmostly the teacher-establishment because in any case countereducation - or reeducationproducing life and social environment in which they grow technologized youth is a force that competes with the transmission of knowledge organized and sequenced regulated processes of education. To enable that countereducation doesn't interfere and, worse, be set against the teaching process. They must take and integrate social instruments that are already being used by young people. Audiovisual communication, multimedia and new possibilities and constraints of the "network society" should be incorporated into the educational track that leads to evolutionary changes in the methodology of education, teaching and learning for both teachers and for students, because as we have seen in this project interactions with new media; new methods and new situations arise causing unforeseen possibilities and unexpected opportunities while students also learn to overcome difficulties.

The Web constitutes an innovative format for content delivery and information exchange. That is one reason why knowledge and use of the Web would justify its inclusion within the curriculum of a university that focuses on technology. "In addition, there are many skills where our students will be developed, adapted, extended or even reinvented in the use of technology as a professional key development through collaborative processes" as future company managers.

\subsection{Defining the concept of web 2.0}

Taken together, these applications form the collaboration platform that social networking applications and their variations, including mash-ups and blogs, rely on in order to accomplish high levels of collaboration. In keeping with unbounded systems thinking, the proliferation of the series of Web 2.0 applications and their growth are defined more by communication patterns than adherence to taxonomies and architectures. This is one of the factors that were taken into account in defining unbounded systems thinking as the method of enquiry. 


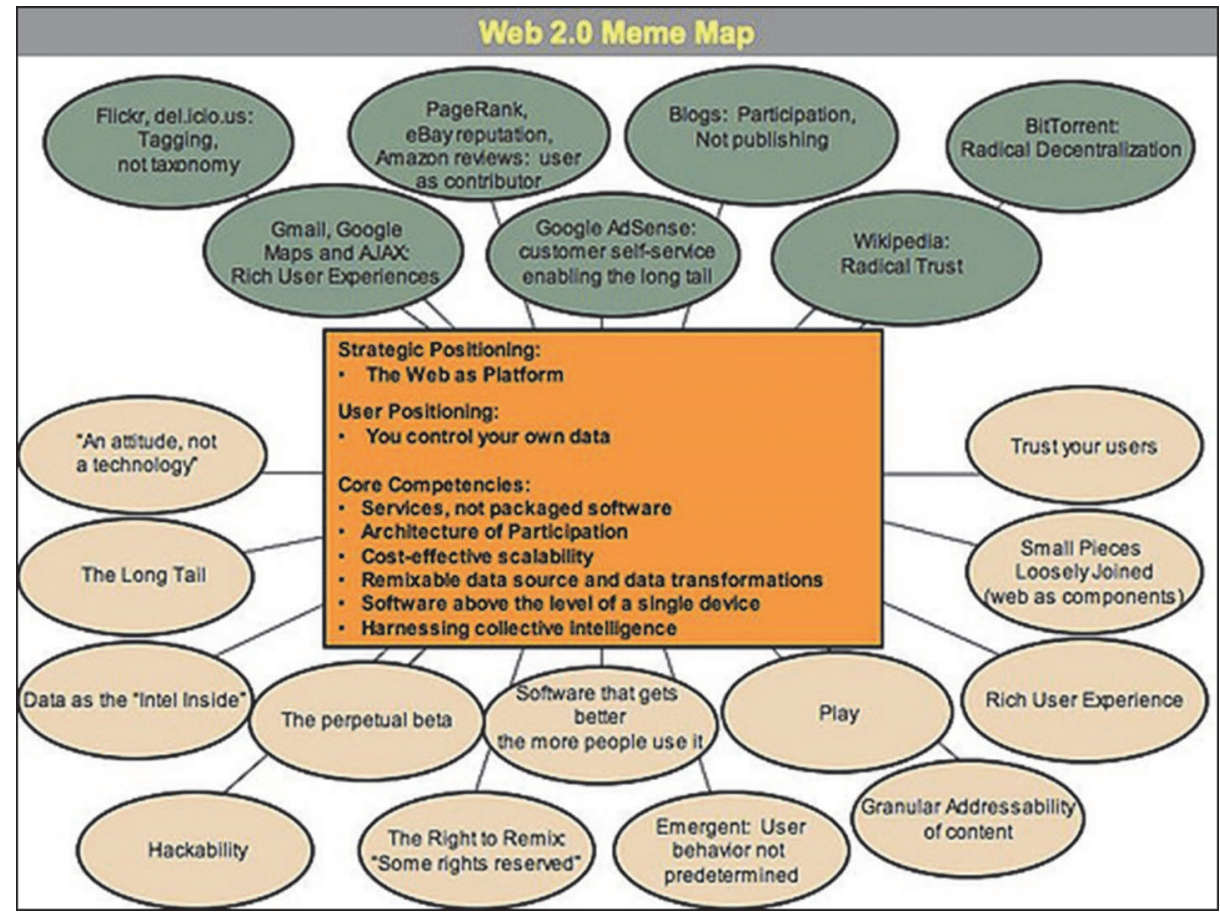

Fig. 1. The map that $\mathrm{O}^{\prime}$ Reilly and Battelle created to show how both market and user dynamics are defining social networking ( $\mathrm{O}^{\prime}$ Reilly, 2005. et.al.).

In order to teach these skills, the pedagogical bases that lay the foundations for the use of the WWW within this project are:

- Communicative Language Teaching (and learning). Students are collaborating in a foreign language in a natural and spontaneous way, so language use is promoted by theirs mere use.

- Learner-centred pedagogy. The students themselves choose topics for interaction, as well its pace and format, according to their personal interests.

- Learning autonomy. The students are co-managers of their own learning process, and therefore take full responsibility for the related training contents, instead of merely digesting information in a passive manner.

- Learning by doing (experiential learning). In order to be able to participate, students must learn -in a practical way- how to get in the new medium and environment of Internet and multimedia formats (image processing, audio and video, etc.).

- Collaborative learning. Students find themselves totally integrated in a virtual learning and exchange community. Interaction with peers is a basic requirement to advance in the learning process.

- Cultural exchange. Students experience first-hand direct contact with the cultural systems, values and environment of their partners on the other side of the world.

Table 1 provides an overview of Web 2.0 applications, illustrating the role of social networking in the next generation of services available on the Internet. 


\begin{tabular}{|l|l|}
\hline Application & Description \\
\hline Blog & $\begin{array}{l}\text { Self-managed personal Web site which is made up of individual entrances } \\
\text { and they are organized by inverse chronology }\end{array}$ \\
\hline Wiki & Web site where any user qualified by the system can easily edit a content \\
\hline Mash-up & Formed hybrid applications from existing applications. \\
\hline $\begin{array}{l}\text { Social } \\
\text { networking }\end{array}$ & $\begin{array}{l}\text { Applications in which any user is able to contact with other users generating } \\
\text { a portfolio of contacts that is manageable. Its business use is the possibility of } \\
\text { being able to identify experts in a concrete subject }\end{array}$ \\
\hline Podcast & $\begin{array}{l}\text { Entrances of multimedia contents of video or audio lodged in applications } \\
\text { type blog. The distribution is similar to each blog post. Its proliferation may } \\
\text { be due to RSS syndication. }\end{array}$ \\
\hline $\begin{array}{l}\text { Social } \\
\text { tagging }\end{array}$ & $\begin{array}{l}\text { Applications that allow classify digital contents by tags, assigned by the user, } \\
\text { being able to share them with other users of the network. }\end{array}$ \\
\hline $\begin{array}{l}\text { Syndication } \\
\text { RSS }\end{array}$ & $\begin{array}{l}\text { It allows the users syndicated to a Web site to be warned of the updates } \\
\text { content without the necessity of going to the Website. It implies the use of a } \\
\text { content tag software (like googlereader, bloglines...) that manages the } \\
\text { syndications of the Websites as wished by the user }\end{array}$ \\
\hline
\end{tabular}

Table 1. An overview of Web 2.0 applications, illustrating the role of social networking in the next generation of services available on the Internet.

\subsection{Web 2.0 in learning and teaching}

Samples of areas and approaches where MIT-UPV has had good effect has been: Group work can often be aided by having social software available - this is no surprise when we note that social software is software that facilitates group process. Thus, for example: blogs can be used in personal writing and the group gives its opinion.

Social constructivism (Vygotsky , 1978) has, as a central precept, that knowledge is created by learners in the context of and as a result of social interaction. Social constructivist approaches are particularly aided by MIT-UPV as mediating mechanisms between collaborating students and between students and teachers, particularly between students who might sometimes be working in different places and at different times. Thus, for example, a group of students might construct a device in a wiki, but also be guided by a teacher who provides the fundamentals in the same wiki.

Constructionism, advocated by Seymour Papert, is particularly amenable to Web 2.0 approaches. In Papert's words 'Constructionism ... shares constructivism's connotation of learning as "building knowledge structures" irrespective of the circumstances of the learning. It then adds the idea that this happens felicitously especially in a context where the learner is consciously engaged in constructing a public entity, whether it is a sandcastle on the beach or a theory of the universe" (Papert, 1991). Thus social software systems can be used for the construction of public entities, for example, via a video presentation on a social media system, a blog entry (for individual work) and a set of wiki pages (for individual and group work).

\subsection{Changes in student population}

Web 2.0 technologies are one of several digital technologies that are increasingly helping change some characteristics of current and future students, and these changes may necessitate profound changes in learning and teaching methods. 
Marc Prensky (1978) defined 'digital natives' as a generation that has grown up with digital technology, operating at "twitch speed", and performing multiple activities simultaneously. Thus Oblinger and Oblinger characterize the next generation ("n-gen") students as digitally literate, highly Internet familiar, connected via networkedmedia, used to immediate responses, preferring experiential learning, highly social ("being a friend of a friend is acceptable"), prefer to work in teams, craving interactivity in image rich environments (as opposed to text intensive environments), and having a preference "for structure rather than ambiguity". Oblinger and Oblinger also point to a different kind of student, one who is nontraditional and working and studying at the same time.

Questions arise: Are these new student skill and preference sets different enough to demand changes in teaching methods to successfully engage with them? Do the skill sets of incoming students demand (possibly only transitional) 'remedial' teaching, for example, in using libraries and finding primary sources? Is the changing student profile going to need different ways of teaching that, e.g., minimise traditional patterns of attendance and increase flexibility in where and when learning takes place? Somewhat anecdotally, there are different perspectives relating to student engagement (and therefore grades and retention):

- We have seen reports of lecturers moving part or all of their electronic course support from traditional virtual learning environments to social networking systems like MySpace and Facebook, because of greater student engagement with these kinds of social networking tool. Web 2.0 enabled approaches may therefore help engage with students. However, there is also evidence that many students see these as "their" space that should not be 'invaded' by faculty (Hewitt, 2006).

- On the other hand, recent student interviews in a UK university revealed that students were not concerned how they are taught (e.g. through lectures, seminars, or through a blended learning approach) as long as the instruction was good. This then raises the question of what is good practice in learning and teaching in different modalities.

The emergence of a computational social science shares with other nascent interdisciplinary fields (e.g., sustainability science) the need to develop a paradigm for training new scholars. A key requirement for the emergence of an interdisciplinary area of study is the development of complementary and synergistic explanations spanning different fields and scales. Tenure committees and editorial boards need to understand and reward the effort to publish across disciplines. Certainly, in the short run, computational social science needs to be the work of teams of social and computer scientists. In the long run, the question will be: should the academic world train computational social scientists, or teams of computationally literate social scientists and socially literate computer scientists?

The emergence of cognitive science in the 1960s and 1970s offers a powerful model for the development of a computational social science. Cognitive science emerged out of the power of the computational metaphor of the human mind. It has involved fields ranging from neurobiology to philosophy to computer science. It attracted the investment of substantial resources to establish a common field, and it has created enormous progress for public good in the last generation. We would argue that a computational social science has a similar potential, and is worthy of similar investments. ${ }^{2}$

${ }^{2}$ Life in the network: the coming age of computational social science. 


\subsection{Possible issues and problems}

An incomplete set of additional problems and issues that arise in relation to MIT-UPV are:

1. Many students work is about content sharing and repurposing. This can easily be seen by students as part of a new teenage copy-and-paste culture that runs counter to traditional notions of plagiarism, and adjustments may need to be made, either to redefine plagiarism (unlikely to occur), or to help students transcend this culture in the environments (more likely to occur).

2. There may be changes in teacher roles like the emphasis on active learning, with creation, communication and participation playing key roles, and on changing roles for the teacher, indeed, even a collapse of the distinction between teacher and student altogether.

3. There may be skills and/or culture crisis as traditional teachers are forced to use unfamiliar tools and work in unfamiliar ways and alien environments.

4. There may be economic factors at work, particularly in a world of broad participation. Not all students may be digitally connected (with a computer and Internet connection) at home or in their halls. These students would be at a profound disadvantage in a new teaching/learning concept world.

The MIT-UPV project was selected in 2010 by publisher Ian Lancashire through its publication Language Learning and technology 3 , as one of the 20 world's most prestigious on-line projects.

\subsection{Conclusions}

The project has two complementary facets, namely, the academic exchange at all levels, and the development of an ideal university model from and for the students. Both of these aspects could evolve in the near future in an independent, yet complementary, way. It is also feasible, as has already been suggested earlier, to work co-operatively towards a deeper understanding of both university systems, and even to take a step ahead towards a university system which better meets the needs and expectations of our students. All this is closely related to total quality management and improvement; a goal for both institutions.

MIT-UPV Exchange provides a nearly-ideal meeting point between teaching innovation and the improvement of global quality within our university systems. Regarding the former aspect (teaching and learning), the project has emerged as a contextualized application of core Internet technology and the World Wide Web to learning and training, both in technical and in international collaborative skills. Concerning the second component (quality), the experience is a powerful tool to assess specific needs, suggestions and problems within the university, always from the point of view of its main clients, the students.

The flexibility of the project makes it even possible to go one step ahead of web-based exchanges and achieve a more direct and personal link between human beings (not only via computers) in both universities.

\section{Metal 2.0 research project: Presentation}

The METAL 2.0 project is a project of collective learning, which lasted for four years; initiated in 2008, where it has been tried to evaluate each one of the 2.0 Web tools and its

\footnotetext{
3 Teaching Literature and Language Online. Ian Lancashire (Ed.) http:/ / www. allbusiness. com/educationtraining/education-systems-institutions/15946766-1. html \# ixzz1d6z72PRu
} 
possible implantation in companies at individual and/or collective level from the accumulated experience managing the infometal marketplace (www.infometal.com) which has conceived for 6 years as one of the first enterprise social networks of the country.

The project is carried out in cooperation between Metal-Processing Technology Institute (AIMME) and the EBIM (Electronic Business Information Management) Group of investigation of the Polytechnic University of Valencia.

Unlike personal social networks (the users register then add their friends or relatives for fun), or professional social networks (the users register, then they add their professional contacts related to purchases/sales, cooperation, etc.), in enterprise social networks, the users are the enterprise associations and they register their associates, and these associates anonymously use the network for purchases/sales, finding out the positions of other companies or extracting data that they may wish to use).

\subsection{Uses of Web 2.0 in metal 2.0 project}

Phase 1: 2008/2009

The EBIM group has identified three phases in the use of Web 2.0. These phases are: the participation of the user, the generation of conversations in the digital environment and the collaborative work. The passage from one stage to another depends on several factors which they emphasize: the culture of use of $2.0 \mathrm{Web}$ and later the degree of relation of the users in the use that is being carried out (it is not the same to work in a common project as to answer a post in a personal blog). The project METAL 2.0 is located within first stage of use of Web 2.0. Within this one it emphasizes with the result of hearing generation. Concretely the potential of relation of Web 2.0 is being operated. Generating a win all environments by taking advantage of the visibility that offers the digital surroundings and the facility to establish relations through content can be gotten to establish work contracts since Internet is talking back every better time the way in than the people we interacted.

\subsection{Action, diffusion and results}

After the day of presentation of the Project 'METAL 2.0: Social networks and Web 2.0 for business enterprises, which was attended by a total of 60 companies; published the videos of the same one in Internet with the purpose of forming free to the user companies of these technologies, and asking for their support in the completion of the survey of the project.

These videos have been an awareness and a woken up of these companies with respect to innovation. A 17,324 downloads in the first 5 months, visitors are from 44 countries, 38 universities, business schools and research centers. Data exceeded all expectations.

After the publication in Internet, the survey got more than 200 answers.

The initiative EXPERIMENT METAL 2.0, with 573 participating companies to date, aims at encouraging ICT's professionals of the companies that still do not use Web 2.0 to find out about these technologies and their environments, to train purchasing and sales manager, so that they begin to experience the use of social networks and make profitable use of its power to obtain many contacts. This way, it would be possible to use their own social networks to spread the ICT and to become familiar with these tools.

As far as the diffusion of the present results of the project, there are 141 references to it: http://www.metal20.org/difusion/ 
As far as collaborators in the diffusion they appear a total of 36 companies and organizations, with CENATIC and CEV as new features. We remind you that any organization and/or company interested in helping in the diffusion can do it free by following the steps indicated in: http://www.metal20.org/colaboradores/

Phase 2: 2010/2011 (Metal Project Crowdsourcing 2.0)

Conclusions of the Report:

Crowdsourcing as a concept is not totally new. It's a word that brings together a considerable number of initiatives that existed long ago, even before the adoption of the term. However, its adoption has significantly facilitated to identify their common features, which have allowed us to study and propose its basic features, critical success factors, failure and environments where its use is advisable.

From the scientific point of view, crowdsourcing can be a dynamic process within companies. By using the collective intelligence of knowledge as a heterogeneous set of users, you can get novel solutions to various business problems, whether new or constantly occurring. Different rewards are offered to users, which can range from financial rewards to the recognition of their work that users will participate.

From a business standpoint, it is important to understand:

- What is the logical scenario to implement a crowdsourcing initiative and also to understand their advantages and disadvantages.

- What are the steps that must be considered when launching an initiative like this:

- The company identifies and clearly defines the problem to be solved;

- It should raise the question and challenge the par4ticipants with the reward;

- Work with the participants to energize and clarify doubts or unclear aspects;

- The host provides ideas and proposals;

- The company (or the participants themselves) chooses ideas considered as winners;

- $\quad$ Rewarding the winner or winners;

- Transfer (if so agreed) to the company the rights to use the ideas.

- What are the critical factors to take into account to make the initiative successful:

- Clearly define what is expected;

- Establish the proper reward, not just monetary;

- Management of the community and building on ideas,

- Selection process must be transparent and clear, ideally chosen by the group.

If you consider the main factors listed above and other factors which the company may consider necessary, they may be linked to the collective intelligence of a group to solve problems and innovate complex priority with a much greater diversity of opinion and paying only for what is considered as success.

To conclude the report, highlighting the role of crowdsourcing as a good catalyst for the innovation processes of companies, incorporating collective intelligence, open innovation and collaborative spirit in the task is not easy to adopt nowadays. The pioneers, who open new roads, will be those who are called to form this new partnership between all that lies ahead.

\subsection{Conclusion}

After analyzing the relationship between different environments, both corporate and university/research, to generate uptake and retention of users (both present and future) and 
ensure growth in the content generated by them, we note that for to uptake (and that recruiting users is one of the most important crowdsourcing challenges) exist five major solutions:

1. We can require users to make contributions if we have authority to do so (for example, a manager may require 100 employees to help build a company-wide system).

2. We can pay users. Mechanical Turk ${ }^{4}$ for example provides a way to pay users on the web to help with a task.

3. We can ask for volunteers. This solution is free and easy to execute, and hence is most popular. Most current CS systems on the Web (such as Wikipedia, YouTube) use this solution. The downside of volunteering is that it is hard to predict how many users we can recruit for a particular application.

4. The fourth solution is to make users pay for service. The basic idea is to require the users of a system A to pay" for using A, by contributing to a CS system B......

5. The fifth solution is to piggyback on the user traces of a well-established system (such as building a spelling correction system by exploiting user traces of a search engine). This gives us a steady stream of users. But we must still solve the difficult challenge of determining how the traces can be exploited for our purpose.

Once we have selected a recruitment strategy, we should consider how to further encourage and retain users. Many encouragement and retention (E\&R) schemes exist. We briefly discuss the most popular ones. First, we can provide instant gratification, by immediately showing a user how his or her contribution makes a difference. Second, we can provide an enjoyable experience or a necessary service, such as game playing (while making a contribution). Third, we can provide ways to establish, measure, and show fame/trust/ reputation. Fourth, we can set up competitions, such as showing top rated users. Finally, we can provide ownership situations, where a user may feel he or she "owns" a part of the system, and thus is compelled to "cultivate" that part. For example, zillow.com displays houses and estimates their market prices. It provides a way for a house owner to claim his or her house and provide the correct data (such as number of bedrooms), which in turn helps improve the price estimation.

These E\&R schemes apply naturally to volunteering, but can also work well for other recruitment solutions. For example, after requiring a set of users to contribute, we can still provide instant gratification, enjoyable experience, fame management, and so on, to maximize user participation. Finally we note that deployed CS system often employ a mixture of recruitment methods (such as bootstrapping with "requirement" or "paying", then switching to "volunteering" once the system is sufficiently "mature").

\section{Final conclusion}

Many experts conclude that the crowdsourcing can be applied to a wide variety of problems, and that it raises numerous interesting technical and social challenges. Given the success of current CS systems, they expect that this emerging field will grow rapidly. In the near future, they foresee three major directions: more generic platforms, more applications and structure, and more users and complex contributions.

4 The Amazon Mechanical Turk (MTurk) is a crowdsourcing Internet marketplace that enables computer programmers (known as Requesters) to co-ordinate the use of human intelligence to perform tasks that computers are unable to do yet. 
First, the various systems built in the past decade have clearly demonstrated the value of crowdsourcing. The race is now on to move beyond building individual systems, toward building general CS platforms that can be used to develop such system quickly.

Second, they expect that crowdsourcing will be applied to ever more types of applications. Many of these applications will be formal and structured in some sense, making it easier to employ automatic techniques and to coordinate them with human users. In particular, a large chunk of the Web is about data and services. Consequently, they expect crowdsourcing to build structured database and structured services (Web services with formalized input and output) will receive increasing attention.

Finally, They expect many techniques will be developed to engage and ever broader range of users in crowdsourcing, and to enable them, especially naïve users, to make increasingly complex contributions, such as creating software programs and building mashups (without writing any code), and specifying complex structured data pieces ( without knowing any structured query languages).

\subsection{Final thoughts ${ }^{5}$}

The networks have a life. They grow, change, reproduce, survive and die. A social network is a kind of super human, with an anatomy and physiology of their own. Social networks can develop a type of intelligence that increases or supplements individual intelligence.

\section{Acknowledgments}

To MIT Organization/Department: Douglas Morgenstern \& Adolfo Plasencia URL: http:// mitupv.mit.edu/

To AIMME: Santiago Bonet: http://www.metal20.org/

\section{References}

AIMME - Instituto Tecnológico Metalmecánico.(2011) El arte del crowdsourcing. http://metal20.org/crowds11.

AUI. La sociedad de la información en España (2006). 2007. http:/ / aui.es/index.php?body=est_v1article\&id_article $=1947$

La sociedad de la información en España (2010). Informes 2008.2009.2010.(11ª edición) http:/ / sociedadinformacion.fundacion.telefonica.com/DYC/SHI/InformesSI/secc ion $=1190 \&$ idioma $=$ es_ES.do

Baviera, T. ¿Qué aportan los blogs? (2007). http://www.conoze.com/doc.php?doc=7642

CAMPUS TECHNOLOGY, (2011)Students as Designers and Content Creators: An Online Multimedia Exchange between the U.S. and Spain

http:/ /campustechnology.com/Articles/2003/09/Students-as-Designers-andContent-Creators-An-Online-Multimedia-Exchange-between-the-US-andSpain.aspx

Carr, N. The amorality of Web 2.0. (2005). http://www.roughtype.com/archives/2005/10/the_amorality_o.php

Carr, N. (2003), "it doesn't matter", Harvard business review.

Cornellá, A. (2005) Infoxicación. http:// www.infonomia.com/blog/perm.php?id=2694 
Christakis, Nicholas A., Fowler, James H. Connected. (2010).The suprising power of our Social Networks and How they shape our lives. Santillana.

Davey, D., Gade Jones, K. \& Fox, J., (1995), "Multimedia for Language Learning: Some course design Issues", E-Journal article: Computer Assisted Language Learning, 8/1, pp.31-44

Dawson, R., (2007), Launching the web 2.0. Framework. (30-05-2007) http://www.rossdawsonblog.com/weblog/archives/2007/05/launching_the_w.html

Anhai Doan, Raghu Ramakishnan, \& Alon Y.Halevy, (2011), Crowdsourcing systems on the world-wide web, Communications of the ACM (Vol.54, Issue 4, April 2011).

Ebersbach, A., Glaser, M., \& Heigl, R. (2006). Wiki: Web collaboration. Germany: SpringerVerlag.

Fumero, A. \& Genís, R. (2006), Web 2.0. Fundación Orange.

Gilchrist, A. (2007), "Can Web 2.0 be Used Effectively Inside Organisations?", Bilgi Dünyasý pp. 123-139.

Gonzalez A. (2011), Tu reputación en internet -Trei. http://antonio-gonzalez.info/ http:/ / creoeninternet.com/antonio-gonzalez-reputacion-en-internet-trei/

Granovetter, M. (1973), "The strength of weak ties", American journal of sociology, vol. 78, pp. $1360-1380$

Haworth, W. "The Internet as a Language Learning Resource." In Proceedings Eurocall '95. Edited by A. Gimeno. Valencia: Universidad Politécnica de Valencia, 1995

Hewitt, A and Forte A,(2006) Crossing Boundaries: Identity Management and Student /Faculty Relationships on the Facebook, CSCW'06, November 4-8, 2006

Keen, A. (2007), The coult of the amateur. How today's internet is killing our culture. Double Day. New York.

David Lazer, Alex (Sandy) Pentland, Lada Adamic, Sinan Aral, Albert Laszlo Barabasi, Devon Brewer, Nicholas Christakis, Noshir Contractor, James Fowler, Myron Gutmann, Tony Jebara, Gary King, Michael Macy, Deb Roy, and Marshall Van Alstyne David Lazer,(2009) Harvard University; Life in the network: the coming age of computational social science http:/ / www.sciencemag.org/content/323/5915/721.short

Levy, M. (1997), Computer-Assisted Language Learning. Context and Conceptualization, Oxford: Clarendon Press, 1997

Levy, P. (2004), Inteligencia colectiva por una antropología del ciberespacio Organización panamericana de la salud. Washington, DC.

http://inteligenciacolectiva.bvsalud.org

McAfee, A.(2006), "Enterprise 2.0: The Dawn of Emergent Collaboration", MIT Sloan management review, vol. 47 , no. 3, pp. 21-28

McAfee, A.(2007b), The ties that find. 1-10-2007b. http://blog.hbs.edu/faculty/amcafee/index.php/faculty_amcafee_v3/the_ties_th at_find/

McAfee, A.(2007a), How to hit the enterprise bulleye. 2007a. http://blog.hbs.edu/faculty/amcafee/index.php/faculty_amcafee_v3/how_to_hit _the_enterprise_20_bullseye/

Mckinsey Quarterly (2007), How businesses are using Web 2.0: A McKinsey Global Survey.

Mintzberg, H. (1973), The Nature of Managerial Work, Ed.Harper \& Row.

MIT OPEN COURSE WARE.(2003) http:/ / ocw.mit.edu/OcwWeb/Foreign-Languages-and-Literatures/21F703Espanol-IIISpring2003/CourseHome/

MIT COMPARATIVE MEDIA STUDIES PROGRAM (2011) Applied Humanism 
http:/ / web.mit.edu/cms/Design/applied.html

Nunan, D.(1988), The Learner-centred Curriculum, Cambridge: Cambridge University Press, 1988

Pérez, L., The Effectiveness of Internet in the Foreign Language Classroom", Horizon http:/ / horizon.unc.edu (2011/11)

Morris, M., Schindehutte, M., \& Allen, J. (2005), "The entrepreneur's business model: toward a unified perspective", Journal of business research.

Orihuela, J. L. (2006), La revolución de los blogs. Cuando las bitácoras se convirtieron en el medio de comunicación de la gente. Ed.Madrid: la esfera de los libros.

O'Reilly, T.(2005) What is web 2.0 Design patterns and business models for the next generation of software. 2005.

http://www.oreillynet.com/pub/a/oreilly/tim/news/2005/09/30/what-is-web20.html

Rappa, M. digitalenterprise.(2007-2011). http:/ /www.digitalenterprise.org

Dans, E. (2010), El mundo tras la Web 2.0 es más democrático, http:/ / www.enriquedans.com/2010/11/el-mundo-tras-la-web-2-0-es-masdemocratico-en-diario-de-avisos.html

Dans, E., (2007), La empresa y la web 2.0.

http://www.enriquedans.com/2007/06/la-empresa-y-la-web-20-articulo-enharvard-deusto.html

Skehan, P. (1996), "Second Language Acquisition Research and Task-based Instruction”, in Willis, J. \& Willis, D. (eds.), Challenge and Change in Language Teaching, Oxford: Heinemann, 1996, p.20.

SYLLABUS. (2011) Students as Designers and Content Creators: An Online Multimedia Exchange between the U.S. and Spain.

http:/ / www.campus-technology.com/article.asp?id=8293

Web 2.0 in Wikipedia (English): http://en.wikipedia.org/wiki/Web_2

Anibal de la Torre (2006) Web Educativa 2.0, Edutec. Revista Electrónica de Tecnología Educativa, Núm. 20, Enero 06 http://www.uib.es/depart/gte/gte/edutec-e/revelec20/anibal20.htm

Widdowson, H. G. (1978), Teaching Language as Communication, Oxford: Oxford University Press, 1978.

Weinberger, D. (2007), Everything is miscellaneous. The Power of the New Digital Disorder Times Books. New York 


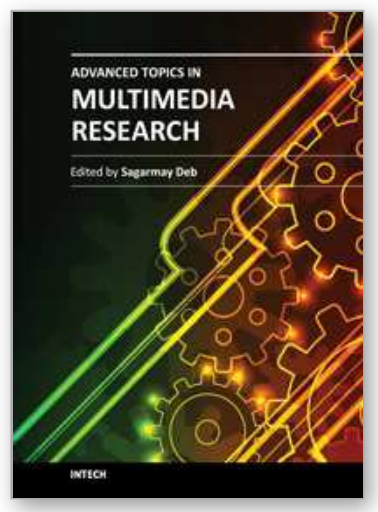

\author{
Advanced Topics in Multimedia Research \\ Edited by Dr. Sagarmay Deb
}

ISBN 978-953-51-0078-2

Hard cover, 104 pages

Publisher InTech

Published online 17, February, 2012

Published in print edition February, 2012

As multimedia has become a very important technology, significantly improving people's lives, this book provides an up-to-date scenario of various fields of research being carried out in the area. The book covers topics including web-based co-operative learning, effective distance learning through multimedia, quality control of multimedia on the internet, recovery of damaged images, Network-on-Chip (NoC) as a global communication vehicle, and Network GPS for road conditions (such as traffic and checkpoints). We believe that the book will help researchers in the field to proceed further in their research on multimedia.

\title{
How to reference
}

In order to correctly reference this scholarly work, feel free to copy and paste the following:

Gil Pechuán Ignacio, Conesa Garcia M. Pilar and Peris Ortiz Marta (2012). Social Networking and Science Research: The MIT-UPV and Metal 2.0 Cases, Advanced Topics in Multimedia Research, Dr. Sagarmay Deb (Ed.), ISBN: 978-953-51-0078-2, InTech, Available from: http://www.intechopen.com/books/advanced-topicsin-multimedia-research/social-networking-and-science-research-the-mit-upv-and-metal-2-0-cases

\section{INTECH}

open science | open minds

\section{InTech Europe}

University Campus STeP Ri

Slavka Krautzeka 83/A

51000 Rijeka, Croatia

Phone: +385 (51) 770447

Fax: +385 (51) 686166

www.intechopen.com

\section{InTech China}

Unit 405, Office Block, Hotel Equatorial Shanghai

No.65, Yan An Road (West), Shanghai, 200040, China

中国上海市延安西路65号上海国际贵都大饭店办公楼 405 单元

Phone: +86-21-62489820

Fax: +86-21-62489821 
(C) 2012 The Author(s). Licensee IntechOpen. This is an open access article distributed under the terms of the Creative Commons Attribution 3.0 License, which permits unrestricted use, distribution, and reproduction in any medium, provided the original work is properly cited. 